\title{
ANALISIS SISTEM JARINGAN TRANSPORTASI DAN MODEL GRAVITASI DI KOTA AMBON
}

\author{
Surakanti Wardono \\ Paulus A. Pangemanan \\ Charles R. Ngangi
}

\begin{abstract}
This study aimed to analyze the maximum capacity of roads in overcoming bottlenecks using the Maximum Network Flow Model and analyze the interaction of the distribution of the movement with the city located around the city of Ambon by using Gravity Model. Data obtained using the method of documentation. Obtained results, the maximum number of cars that can pass through the road network in 1 hour is 68 units. Line 1 is the terminal Mahardika to Kudamati has exceeded the capacity for the first hour there are 104 units of the car were gone and behind 102 cars. While the other track is still low, so that the growth and development of land transportation is strongly recommended. Results of the analysis of the gravitational interaction with the transport of the most powerful city of Ambon is Karang Panjang Town with great interaction and 6781.96088 weakest interaction is with great interaction Leahari City 5.27899.
\end{abstract}

Keywords: congestion, maximum capacity, network model, maximum flow, gravity model.

\section{ABSTRAK}

Penelitian ini bertujuan untuk menganalisis kapasitas maksimum ruas jalan dalam mengatasi kemacetan dengan menggunakan metode Model Jaringan Maximum Flow serta menganalisis interaksi sebaran pergerakan dengan kota yang berada di sekitar Kota Ambon dengan menggunakan metode Model Gravitasi. Data diperoleh dengan menggunakan metode dokumentasi. Diperoleh hasil, jumlah maksimal mobil yang dapat melalui jaringan jalan dalam 1 jam adalah 68 unit mobil. Jalur 1 yaitu terminal mahardika ke Kudamati telah melebihi kapasitas karena dalam 1 jam terdapat 104 unit mobil yang pergi dan balik 102 unit mobil. Sedangkan jalur yang lain masih rendah, sehingga pertumbuhan dan pengembangan transportasi darat sangat disarankan. Hasil analisis interkasi gravitasi transportasi yang paling kuat dengan Kota Ambon adalah Kota Karang Panjang dengan besar interaksi dan 6781,96088 interaksi yang paling lemah adalah Kota Leahari dengan besar interkasi 5,27899.

Kata Kunci: kemacetan, kapasitas maksimum, model jaringan, maximum flow, model gravitasi.

\section{PENDAHULUAN}

Lalu lintas sebagai bagian dari Sistem Transportasi Nasional yang dapat mendorong pertumbuhan ekonomi suatu daerah karena lalu lintas yang diatur dengan baik akan menjadi pendorong terhadap kegiatan-kegiatan ekonomi. Sebagai ibukota Provinsi Maluku, kota Ambon terdahulu merupakan pusat administrasi serta pusat aktivitas perdagangan dan jasa yang paling berkembang di daerah Indonesia timur. Akan tetapi ketika terjadi konflik sosial, pembangunan di pulau Ambon menjadi terhenti. Setelah konflik berakhir Ambon kembali berbenah dan mulai melakukan pembangunan dimana-dimana. Seiring dengan pembangunan tersebut, pertumbuhan penduduk di Kota Ambon dan juga pertumbuhan perekonomian masyarakat terus berkembang. Karena itu mobilitas masyarakat dalam aktifitas sehari-hari terus meningkat.

Permasalahan yang umum ditemukan dalam lalu lintas baik di kota-kota besar maupun daerah berkembang lainnya adalah masalah kemacetan yang diakibatkan oleh pengaturan lalu lintas yang tidak tepat ditambah infrastruktur jalan yang tidak memadai menambah parahnya kemacetan. Kemacetan juga dapat disebabkan karena volume lalu lintas melebihi kapasitas yang ada. Suatu ruas jalan atau segmen jalan tertentu memiliki kapasitas yang tidak selalu sama begitu juga dengan volume arus yang melaluinya khususnya Kota Ambon. Pengaturan arah lalu lintas yang selama ini dilakukan tidak mempertimbangkan besar arus kendaraan, sementara pertumbuhan kendaraan di 
kota Ambon tidak dapat dikendalikan. Oleh karena itu perlu dilakukan analisa jaringan transportasi kendaraan berdasarkan kapasitas ruas jalan agar kendaraan bisa dikendalikan sehingga kemacetan bisa diurai.

\section{METODOLOGI PENELITIAN}

\section{Jenis Data}

Penelitian ini menggunakan data sekunder dengan periode pengamatan tahun 2013 - 2014. Datadata ini diperoleh dari berbagai penerbitan yang dikeluarkan oleh Badan Pusat Statistik Provinsi Maluku dan Kota Ambon dari kantor atau dinas yang terkait dengan penelitian ini. Data-data ini meliputi:

a. Jumlah jurusan/trayek angkutan kota yang ada di Kota Ambon

b. Daerah/ wilayah yang dilalui angkutan kota

c. Jumlah angkot (per unit) yang beroperasi dalam 1 hari

d. Jarak antar wilayah di Kota Ambon

e. Jumlah penduduk Kota Ambon

f. Pergerakan jumlah penduduk di Kota Ambon dan sekitar wilayah

\section{Metode Pengumpulan Data}

Metode pengumpulan data dan informasi yang berhubungan dengan masalah yang akan dibahas dalam penelitian ini menggunakan metode dokumentasi yaitu pengumpulan data dan informasi dilakukan dengan cara membaca, memahami dan mempelajari buku-buku terbitan dari kantor atau dinas yang terkait dengan penelitian ini, artikel-artikel, jurnal-jurnal, dan buku-buku yang mempunyai relevansi dengan masalah yang diangkat dalam penelitian ini, yang diperoleh melalui perpustakaan dan download internet.

\section{Analisis Data menggunakan Model Jaringan Maximal Flow}

Analisis ini digunakan untuk mencari jumlah kapasitas jaringan transportasi darat dalam hal ini angkot pada beberapa jurusan di kota Ambon. Model Jaringan Maximal Flow di analisis dengan menggunakan program aplikasi Quantitive Management for Windows dimana data - data yang diperoleh dimasukan ke dalam program menurut jalur-jalur yang telah ada sehingga diperoleh hasil jaringan dan iterasi yang menjadi solusi dari permasalahan di atas.

\section{Analisis Data Menggunakan Model Gravitasi}

Analisis ini digunakan untuk mencari wilayah mana di sekitar Kota Ambon yang berpotensi kuat dalam pertumbuhannya. Adanya interaksi antara daerah menunjukkan eratnya hubungan antara wilayah 1 dengan wilayah 2 sebagai konsekuensi interaksi daerah dalam teori pusat pertumbuhan. Carrothers dalam Tarigan (2004) telah menganalogikan formulasi interaksi dengan hukum gravitasi, yang dijabarkan sebagai berikut:

Keterangan :

$$
\mathbf{I}_{\mathrm{i}, \mathrm{j}}=\frac{\left(\mathbf{P}_{\mathrm{i}} \mathbf{P}_{\mathrm{j}}\right)}{\left(\mathbf{D}_{\mathrm{i}, \mathrm{j}}\right)^{\mathbf{2}}}
$$

$\mathrm{I}_{\mathrm{i}, \mathrm{j}}$ : Interaksi dalam wilayah 1 dan 2

$\mathrm{P}_{\mathrm{i}}$ : Jumlah penduduk wilayah 1

$\mathrm{P}_{\mathrm{j}}$ : Jumlah penduduk wilayah 2

$\mathbf{J}_{1,2}$ : jarak antara wilayah 1 dan 2 (dalam meter)

Nilai $I_{i, j}$, menunjukkan eratnya hubungan antara wilayah 1 dan 2, semakin besar nilai $\mathrm{I}_{\mathrm{i}, \mathrm{j}}$, maka semakin erat hubungan antara dua wilayah, dengan demikian semakin banyak pula perjalanan ekonomi yang terjadi sebagai konsekuensi interaksi kota-desa dalam regional (Badrudin dalam Jamzani Sodik dan Nia Septia Ardyani, 2005)

\section{HASIL DAN PEMBAHASAN}

\section{Analisis Jaringan Maximum Flow Menggunakan QM}

Pada tahap ini suatu jaringan jalan direpresentasikan kedalam graf dengan graf yang memiliki arah dan bobot. Jaringan adalah suatu sistem yang terdiri dari titik dan garis-garis yang menghubungkan titik-titik tersebut. Jaringan dapat direpresentasikan dengan baik melalui graf (Siang,2011). Yang dimaksud dengan arah adalah sistem arah dari suatu arus yaitu sistem satu arah atau dua arah, sedangkan bobot adalah kapasitas jalan dalam menampung kendaraan atau jumlah maksimal kendaraan yang dimungkinkan untuk melewati jalan atau segmen jalan tertentu. Dalam graf berlabel, setiap garis diasosiasikan dengan suatu bilangan riil yang menunjukkan bobot hubungan antara kedua titik (Siang,2011). 


\section{Gambar 1. Peta Jaringan Jalan Kota Ambon}
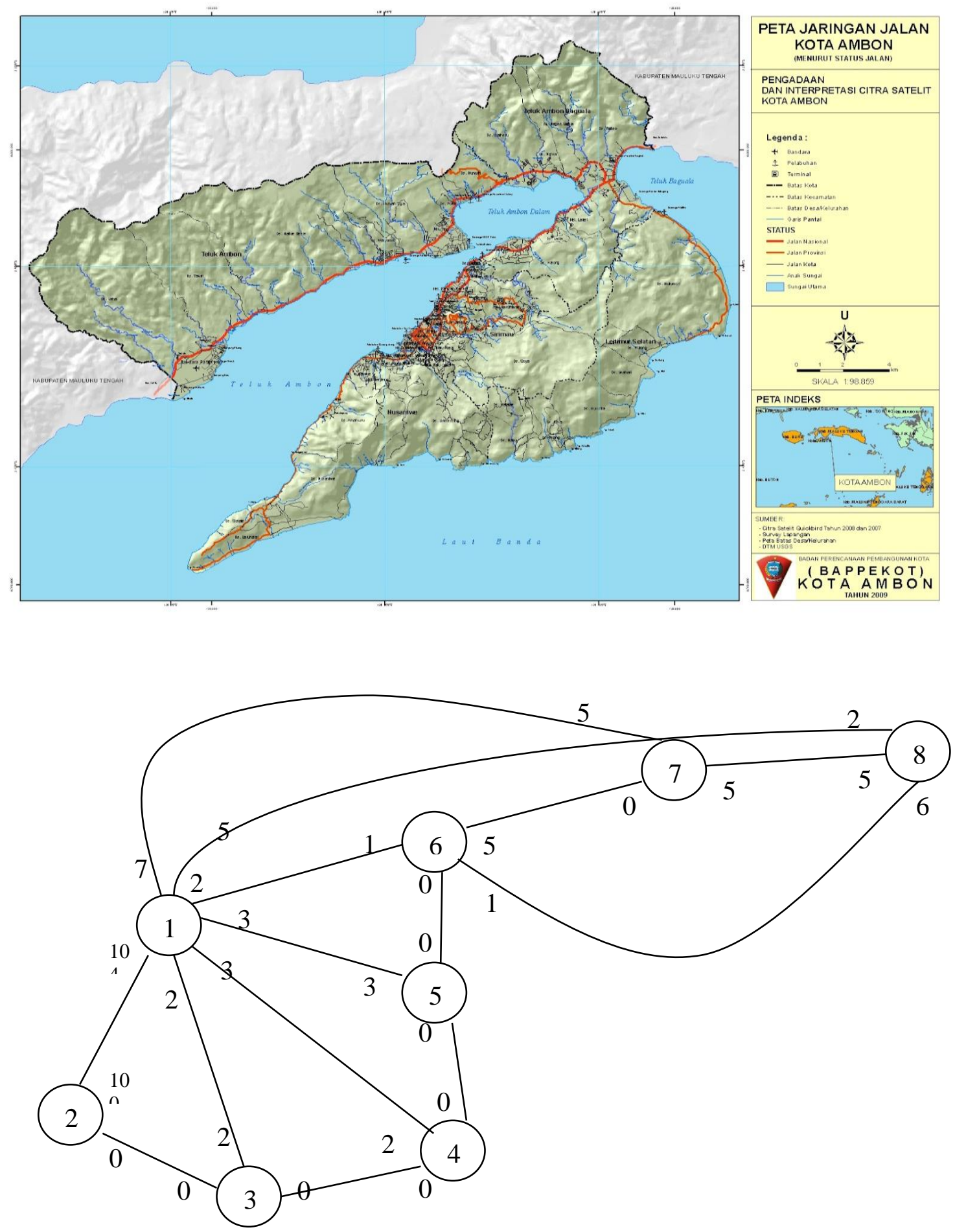

Gambar 2. Simulasi Jaringan Transportasi Beberapa Daerah di Kota Ambon 
Tabel 1. Keterangan dari Jaringan Transportasi yang diteliti

\begin{tabular}{cl}
\hline Wilayah & \multicolumn{1}{c}{ Nama Kota/ Desa } \\
\hline 1 & Terminal Mardika/ Pusat Kota \\
2 & Kudamati \\
3 & Soya \\
4 & Karang Panjang \\
5 & Batu Merah \\
6 & Galala \\
7 & Lateri \\
8 & Passo \\
\hline
\end{tabular}

\section{Sumber: Data Primer}

Simulasi dilakukan pada ruas jalan terbatas di Kota Ambon Berdasarkan peta jalan dipilih beberapa ruas jalan namun tetap dalam suatu jaringan jalan sehingga semua ruas jalan terpilih tetap terkoneksi. Setelah menentukan ruas jalan kemudian direpresentasikan kedalam graf. Setiap ruas jalan diberi label dan bobot yang terdiri dari arus dan kapasitas.
Untuk menyelesaikan masalah aliran maksimum menggunakan software QM, maka dilakukan langkahlangkah yang telah dijelaskan pada bab sebelumnya. Dari langkah tersebut diperoleh akhir atau solusi dari pencarian aliran maksimum pada jaringan transportasi Kota Ambon. Berikut hasil output pencarian aliran maksimum dengan software QM for Windows.

Tabel 2. Tampilan output masalah aliran maksimum

\begin{tabular}{|c|c|c|c|c|c|c|}
\hline & & & & & & (untitled) Solution \\
\hline Branch name & Start node & End node & Capacity & $\begin{array}{l}\text { Reverse } \\
\text { capacity }\end{array}$ & Flow & \\
\hline Maximal Network Flow & 68 & & & & & \\
\hline jalur 1 & 1 & 2 & 104 & 102 & 0 & \\
\hline jalur 2 & 1 & 3 & 2 & 2 & 0 & \\
\hline jalur 3 & 1 & 4 & 37 & 20 & 0 & \\
\hline jalur 4 & 1 & 5 & 3 & 3 & 0 & \\
\hline jalur 5 & 1 & 6 & 20 & 15 & 15 & \\
\hline jalur 6 & 1 & 7 & 7 & 5 & 0 & \\
\hline jalur 7 & 1 & 8 & 53 & 25 & 53 & \\
\hline jalur 8 & 2 & 3 & 0 & 0 & 0 & \\
\hline jalur 9 & 3 & 4 & 0 & 0 & 0 & \\
\hline jalur 10 & 4 & 5 & 0 & 0 & 0 & \\
\hline jalur 11 & 5 & 6 & 0 & 0 & 0 & \\
\hline jalur 12 & 6 & 7 & 5 & 0 & 5 & \\
\hline jalur 13 & 6 & 8 & 10 & 6 & 10 & \\
\hline jalur 14 & 7 & 8 & 5 & 5 & 5 & \\
\hline
\end{tabular}

Dari hasil analisis penyelesaian menggunakan algoritma software QM, memperoleh aliran maksimum dari jaringan kendaraan Kota Ambon berdasarkan gambar yang dibuat dari simpul 1 ke simpul 8, dihasilkan aliran maksimum dengan sebesar
68 unit angkot. Aliran maksimum sebesar 68 unit pada jaringan tersebut mempunyai arti bahwa apabila jaringan tersebut dialiri arus lebih dari 68 unit akan terdapat sisi yang dalam hal ini adalah kendaraan yang lewat melebihi kapasitasnya ruas jalan. 
Tabel 3. Iterasi Hasil Pengolahan Data

\begin{tabular}{|c|c|c|c|}
\hline \multirow[b]{2}{*}{ Iteration } & \multicolumn{3}{|l|}{ (untitled) Solution } \\
\hline & Path & Flow & Cumulative Flow \\
\hline 1 & $1 \rightarrow 8$ & 53 & 53 \\
\hline 2 & $1->6->8$ & 10 & 63 \\
\hline 3 & $1->6->7->8$ & 5 & 68 \\
\hline
\end{tabular}

Dari angka pada Tabel 3 Iterations, dapat diketahui bahwa jumlah maksimal mobil yang dapat melalui jaringan jalan dari dalam 1 jam adalah

1. Melalui jalur $1 \Rightarrow 8$ sebanyak 53 unit mobil

2. Melalui jalur $1 \Rightarrow 6 \Rightarrow 8$ sebanyak 10 unit mobil

3. Melalui jalur $1 \Rightarrow 6 \Rightarrow 7 \Rightarrow 8$ sebanyak 5 mobil

\section{Analisa Interkasi Antar Wilayah menggunakan Model Gravitasi}

Teori gravitasi dapat digunakan untuk melihat interaksi keruangan antar kota. Dalam kaitannya dengan interaksi dalam transportasi, dalah hal ini dikaitkkan dengan keberadaan jalan yang menghubungkan antar kota-desa. Dalam tulisan ini, kekuatan interaksi dihitung berdasarkan kota dan ibukota kecamatan

Tabel 4. Hasil Perhitungan Interaksi Model Gravitasi Antar wilayah

\begin{tabular}{llccr}
\hline Ibu kota & \multicolumn{1}{c}{$\begin{array}{c}\text { Kota } \\
\text { kecamatan }\end{array}$} & $\begin{array}{c}\text { Jarak } \\
(\mathrm{km})\end{array}$ & $\begin{array}{c}\text { Jumlah } \\
\text { penduduk }\end{array}$ & \multicolumn{2}{c}{ Besar interaksi } \\
\hline Ambon & Amahusu & 9,00 & 102.986 & 421,16696 \\
& Karang & $\mathbf{2 , 8 0}$ & $\mathbf{1 6 0 . 5 1 3}$ & $\mathbf{6 7 8 1 , 9 6 0 8 8}$ \\
& Panjang & & & 25,34093 \\
& Wayame & 24,00 & 44.064 & 140,96466 \\
& Passo & 12,00 & 61.279 & $\mathbf{5 , 2 7 8 9 9}$ \\
& Leahari & $\mathbf{2 6 , 0 0}$ & $\mathbf{1 0 . 7 7 3}$ &
\end{tabular}

Sumber: Data Primer Diolah

Kekuatan Gravitasi antar Kota Ambon dengan Kota-desa Kecamatan dapat dilihat pada Tabel 4. Kekuatan gravitasi tertinggi yaitu interaksi antara Kota Ambon dengan Kota Karang Panjang dengan nilai kekuatan gravitasi 6781,96088. Sedangkan kekuatan gravitasi terendah antara Kota Ambon dengan Kota Leahari dengan nilai kekuatan gravitasi 5,27899 .

Dalam melakukan perhitungan gravitasi ini, asumsi jarak yang digunakan diukur dari jarak terpendek jalan yang menghubungkan Kota Ambon dengan kota-kota yang bersangkutan. Asumsi fasilitas jalan diasumsikan sama untuk mempermudah perhitungan karena faktor adanya hambatan tersebut akan menyulitkan proses perhitungan dalam mencari nilai interaksi.

Kota Karang Panjang merupakan kota yang memiliki jumlah penduduk terbanyak di Kota Ambon. Hasil perhitungan interaksi gravitasi antara Kota Ambom dengan Kota Karang Panjang menunjukkan angka tertinggi. Hal ini menggambarkan tingkat interkasi yang terjadi antara kedua kota merupakan 
yang tertinggi. Mobilitas antara kedua kota tersebut merupakan yang tertinggi. Tentunya, implikasi dari mobilitas yang tersebut yaitu interaksi kegiatan ekonomi antara kedua kota tersebut tinggi. Disamping itu, faktor jarak antara kedua kota yang dekat $(2,80$ $\mathrm{km}$ ) mempermudah akses berpindah dan beraktivitas antara kedua kota.

Kota dengan kekuatan interaksi gravitasi terendah yaitu Kota Leahari. Hal ini mengindikasikan interaksi antara Kota Ambon dengan Kota Leahari sangat rendah. Dalam hal ini mobilitas dan kegiatan ekonomi. Faktor jarak disini memiliki pengaruh dalam menghambat atau membuat interaksi antara kedua kota menjadi rendah. Sehingga perlu adanya penyeberan pembangunan infrastruktur jalan alternatif yang dapat memperpendek jarak sehingga dapat menigkatkan mobilitas dan kegiatan ekonomi di daerah tersebut.

\section{KESIMPULAN DAN SARAN}

\section{Kesimpulan}

Berdasarkan hasil dan pembahasan maka dapat disimpulkan bahwa :

1. Aliran maksimum jaringan kendaraan Kota Ambon sebesar 68 unit angkot. Jalur transportasi yang melebihi kapasitas adalah jalur Terminal Mahardika ke Kudamati, sedangkan jalur lainnya dibawah kapasitas penggunaan jalan dalam 1 jam.

2. Kota Karang Panjang merupakan kota yang memiliki jumlah penduduk terbanyak di Kota Ambon. Hasil perhitungan interaksi gravitasi antara Kota Ambon dengan Kota Karang Panjang menunjukkan angka tertinggi. Hal ini menggambarkan tingkat interkasi yang terjadi antara kedua kota merupakan yang tertinggi. Sedangkan kota dengan kekuatan interaksi gravitasi terendah yaitu Kota Leahari. Hal ini mengindikasikan interaksi antara Kota Ambon dengan Kota Leahari sangat rendah. Dalam hal ini mobilitas dan kegiatan ekonomi sangat rendah dengan asumsi wilayah kecamatan Laehari pertumbuhan dan pengembangannya sangat lambat. Faktor jarak disini memiliki pengaruh dalam menghambat atau membuat interaksi antara kedua kota menjadi rendah.

\section{Saran}

Dari hasil studi jaringan transportasi untuk mengurai kemacetan serta interaksi antar wilayah di Kota Ambon dapat dijadikan pertimbangan atau pegangan bagi pemerintah Kota Ambon dalam mengurai kemacetan dan kesemarawutan kendaraan yang terjadi di Kota Ambon serta dalam penyebaran pembangunan infrastruktur jalan. Juga dapat direkomendasikan alternatif yang dapat memperpendek jarak sehingga dapat meningkatkan mobilitas dan kegiatan ekonomi di daerah - daerah yang memiliki interaksi yang rendah dengan Kota Ambon.

\section{DAFTAR PUSTAKA}

Abubakar, Iskandar. 2001. Antisipasi Bahan Bakar Untuk Transportasi di Indonesia. Jakarta: Direktorat Jenderal Perhubungan Darat.

Adisasmita, Rahardjo. 2008. Pengembangan Wilayah: Konsep dan Teori. Yogyakarta: Graha Ilmu.

Aminah, M, S \& Himawan, C, 2009. Bahan-Bahan Berbahaya Dalam Kehidupan Kenali Produk Sebelum Membeli. Penerbit PT Salamadani Pustaka Semesta, Bandung.

Anonim, 2014. Kota Ambon Dalam Angka. BPS Kota Ambon.

, 2008. Survey Tataran Transportasi Lokal Kota Ambon. Dinas Perhubungan Kota Ambon.

Bafagih, A. 2004. Teorema Min-Cut Max-Flow dan Algoritma Ford-Fulkerson untuk mencari aliran maksimum pada jaringan Transportasi di wilayah Jl. Adi Sucipto Malang. Surakarta : UNS

Banister, D. (1995), "Transport and Urban Development" (Ed.), E and FN Spon, An Imprint of Champman and Hall, London.

Farizal, Thesa. 2012, Pencarian Aliran Maksimum dengan Algoritma Ford-Fulkerson (Studi kasus pada Jaringan Listrik Kota Tegal). Skripsi. Jurusan Matematika, Fakultas Matematika dan Ilmu Pengetahuan Alam, Universitas Negeri Semarang. 
Greenberg, J. 1998. Ford-Fulkerson Max Flow Labeling Algorithm. Tersedia di : http://glossary.computing.society.informs.org/n otes/maxflow-FF.pdf [diakses pada tanggal 20 Juni 2015]

Hobbs, F.D, 1995, Perencanaan dan Teknik Lalu Lintas, Penerbit Gadjah Mada University Press.

Johnsonbaugh, R. 1986. Discrete Mathematics revised edition. New York : Macmillian Publishing Company

Kawet R (2011), Kapasitas dan Tingkat Pelayanan Ruas Jalan Sam Ratulangi Manado pada Kondisi Dua Arah, Jurnal Pendidikan Teknologi dan Kejuruan,Vol.2, Nomor 2 Hal.183-192.

Kodoatie, R.J. (2003), Manajemen dan Rekayasa Infrastruktur, Pustaka Pelajar, Yogyakarta.

Handoyo A.B. (2011), Aplikasi Algoritma Network Flow untuk Manajemen Pendistribusian Minyak, STEI ITB.
Morlok, E.K, (1995), Pengantar Teknik dan Perencanaan Transportasi, Penerbit Erlangga

Lopulalan, Aleksander S. 2010. Study Kawasan Alternatif Untuk Penyangga perkembangan Kota Ambon. Pasca Sarjana Jurusan Arsitektur FTSP ITS Surabaya.

Mumu, C. 2013. Pemodelan Manajemen Lalu Lintas Pada Ruas Jalan Menggunakan Network Flow. Jurusan Teknik Elektro, Fakultas Teknologi Industri Institut Teknologi Sepuluh Nopember. Prosiding Seminar Nasional Manajemen Teknologi XVI Program Studi MMT-ITS, Surabaya.

Parikesit, D. 2007. 1-2-3 Steps: Small steps we can do toward sustainable transport (in Indonesian), Vol. 2: Putting back safety toward better transport, -: The Indonesian Transport Society,

Reksohadiprodjo, Sukanto. 2001. Ekonomi Perkotaan. Yogyakarta : BPFE.

Warpani, Suwardjoko, "Analisis Kota dan Daerah", Edisi ketiga, Penerbit ITB, Bandung, 1984, ISBN No. 979-8591-49-6 